\title{
PÄCIENTES COM AMPUTAÇÃO DE MEMBROS INFERIORES. PROBLEMA DE ENFERMAGEM
}

\author{
* Marlúcia N. Comarú \\ * Celina de Arruda Camargo
}

\section{INTRODUÇAO}

A primeira e mais frequente reação por parte da enfermeira ao tomar conhecimento de que um membro do seu paciente vai ser amputado, é de pena. E é muito natural que assim seja. Seria lamentável se a enfermeira reagisse diferentemente. Entretanto essa pena terá seu aspecto positivo enquanto ela for estímulo para planejar assistência de enfermagem com o objetivo de evitar maiores danos para o paciente, além daqueles impostos pela amputação. É nosso objetivo, neste trabalho, focalizar o aspecto da assistência de enfermagem a pacientes amputados de membros inferiores, tentando demonstrar, tanto quanto possível, que quaisquer que sejam as nossas reações iniciais, há muito que ser feito para minorar e mesmo evitar outros danos para o paciente cujo membro foi amputado.

Dentro desta perspectiva, abordaremos os aspectos cujos conhecìmentos parecem de fundamental importância para o planejamento dos cuidados de enfermagem a pacientes amputados.

\section{ETIOLOGIA}

As causas que levam à amputação de membros inferiores são principalmente: traumatismos, tumores, distúrbios vasculares e infecções. Não se pode precisar quais dessas causas levam mais frequentemente à amputação, no nosso meio. As informações relativas aos dados epidemiológicos, por nós encontradas na literatura, referem-se a outros países. Dr. Rusk, por exemplo (1953) afirma que

* Enfermeiras da Divisão Hospital Ortopedia e Traumatologia do Hospital das Clínicas de S. Paulo. 
anualmente, nos EE.UU., trinta e cinco mil pessoas sofrem amputação devido a acidentes, deformidades congênitas ou cirúrgicas. Ainda em estatística americana proferida por Glatty (1958) encontramos as seguintes informações:

1. - - As amputações por acidentes em homens são 9 vezes maiores que em mulheres.

$2 .^{\circ}$ - As amputações em homens devido a enfermidades são 2,6 vezes maiores que em mulheres.

3..$^{-}$A frequência de amputações devido a tumores é muito semelhante em ambos os sexos.

4.0 - As amputações devidas às deformidades congenitas de extremidades são de frequência semelhante em ambos os sexos.

5..$^{-}$Não há diferença de incidência em membros direito e esquerdo.

6. ${ }^{\circ}$ - Considerando as causas de amputação em relação às faixas etárias temos:

Por trauma, de 41 a 50 anos.

Por enfermidade, de 61 a 70 anos.

Por tumores de 11 a 20 anos.

A análise dos dados estatísticos parece-nos muito importante pelo fato de permitir conhecer a incidência e a frequência das amputações em relação às várias causas. Através destes dados pode-se saber que as amputações por traumas são mais frequentes em adultos de idade média, fase em que se espera do indivíduo grande prođutividade, boas condições físicas e muitos encargos na sociedade. Deve-se, portanto, esperar que estes indivíduos apresentem problemas diferentes daqueles cujas amputações são devidas a enfermidades, e cuja frequência é maior na faixa de 61 a70 anos.

Tanto as condições físicas como as reações frente à amputação, são muito diferente no adolescente, no adulto jovem, no adulto médio e no adulto idoso. Assim colocado o problema é fácil evidenciar a dificuldade de uma abordagem detalhada na tentativa de esgotar o assunto. Por este motivo limita-se este trabalho a alguns aspectos da assistência de enfermagem a pacientes amputados de membro inferior, que nos parecem ser mais importantes para a enfermeira saber, compreender e ser capaz de ensinar ao paciente e família.

Estes aspectos referem-se a: tipos de amputação, níveis de amputação, cuidados nos pré e pós operatórios com ênfase em posições. do paciente, cuidados com o coto, atividades mais comuns que ajudam o paciente a adquirir sua independência e se benefíciar com o processo de reabilitação. 


\section{TIPOS DE AMIPUTAÇÃO}

São dois os tipos de amputação, segundo as causas: aberta e fechada.

Amputações abertas são indicadas a pacientes portadores de gangrena que poderá progredir, ou àqueles que sofrerem esmagamento grave de membro, e cujas condições de contaminação favorecem a instalação de gangrena ou de infecção intensa.

Em toda a circunferência do coto o cirurgião dará pontos de algodão, que uma vez unidos e centralizados, serão tracionados em direção ao eixo do membro amputado; é a chamada tração em paraquedas que suporta, na sua extremidade, quantidade de peso proporcional ao tamanho do coto.

Uma vez verificado pelo cirurgião que já não há mais risco de complicação, será feita a revisão da amputação e dos tecidos deverão ser suturados, transformando a amputação aberta em fechada.

A amputação fechada é realizada quando são afastados os riscos de infecção. A determinação do nível está condicionada à altura da lesão.

\section{NIIVEIS DE AMPUTAÇÃO}

A questão dos níveis de amputação tem sido muito discutida pelos autores que cada vez mais se convencem da real necessidade da utilização de uma prótese. E, ao coto, foi conferida a função de acionar a prótese.

Quando as amputações são realizadas ao nível dos maléolos, o paciente terá mais possibilidade de permanecer períodos longos de pé ou em movimento, e inclusive realizar trabalhos pesados, uma vez que a prótese praticamente vai lhe servir como aumento da base de sustentação.

Até recentemente os autores em geral julgavam que o nível ótimo para amputação da perna, era $7,5 \mathrm{~cm}$. abaixo do joelho, condição indispensável para favorecer o ajustamento do coto à prótese, em relação à distribuição de peso.

Atualmente são confeccionadas próteses de perna que se ajustam a quaisquer níveis de amputação, uma vez que o seu formato permite distribuição perfeita de peso.

Nas amputações acima do joelho os níveis médio e proximal o.o fêmur são os selecionados, por oferecerem melhor capacidade de adaptação à prótese.

As desarticulações devem, sempre que possível ser evitadas. 
Na ocasião em que o cirurgião decide pelo nível da amputação, em geral já está definida a direção da linha de sutura, cuja cicatrização ideal será em primeira intenção.

A preocupação com a sutura não se limita apenas à linha, mas também às condições de cicatrização. O cirurgião, ao seccionar os nervos, irá protegê-los de forma adequada, prevenindo a formação de neuromas que, se ocorrerem, tornarão muito doloroso o processo de deambulação com a prótese.

No pré operatório de pacientes com enfermidades vasculares, e cuja amputação foi programada, o cirurgião estará atento parạ as possíveis complicações.

\section{PRÉ-OPERATÓRIO}

\section{Preparo Psicológico}

O preparo psicológico do paciente está condicionado às causas determinantes da amputação. Nas cirurgias programadas, o médico explicará ao paciente e família as razões desta conduta extrema, e os recursos que poderão ser utilizados no futuro.

Esta é uma das fäses de grande sofrimento para o paciente e família, que precisam compreender e aceitar, como último recurso, a perda de uma parte do corpo. É muito penoso para o paciente aceitar a substituição de uma parte do seu corpo por uma peça mecânica.

A forma de reação diante de tais fatos varia de pessoa para pessoa e na sua maioria é: crise de choro convulso, apatia aparente, negativismo, agressividade, e até idéia de auto-destruição.

Há pacientes, no entanto que, desesperados pelo longo período de dor e incapacidade, aceitam a amputação com certa resignação e objetividade. Eles acham que é a única forma de eliminar a enfermidade e iniciar uma nova etapa da vida.

A enfermeira deverá assistir o paciente, procurando identificar cada uma das suas reações e ajudá-lo nesta fase tão difícil. É essencial que ela acredite que da sua atitude profissional, dependerá o progresso do paciente. Ouvindo suas queixas, conhecendo seus medos, proporcionando meios para elucidar suas dúvidas, ela estará conquistando a confiança do paciente. É a forma de transmitir-lhe a segurança indispensável ao êxito do tratamento.

Sendo possível, a enfermeira deverá levar seu paciente a conhecer outro paciente, amputado, de idade equivalente, em fase de treinamento com prótese e que possa transmitir suas experiências. Este contato tem como objetivo ajudar o paciente a aceitar a nova situação e reformular alguns aspectos de sua vida. 
Preparo físico

Algumas medidas deverão ser tomas com relação ao paciente cuja amputação está prevista. A enfermeira deverá condicionar o paciente a permanecer algumas horas em decúbito ventral e posteriormente dormir nesta posição, com o objetivo de favorecer a extensão dos músculos flexores da coxa, principalmente o potente ileopsoas. Para ajudar no fortalecimento dos músculos triceps crural e biceps, que terão função relevante durante a fase de utilização de muletas, a enfermeira ensinará ao paciente a elevar o tronco, do leito, com auxílio do trapézio da cama; em posição sentada, elevar o corpo.

A prevenção de infecção pós-cirúrgica se inicia no pré-operatório, quando as medidas gerais de higiene corporal deverão ser seguidas. Tricotomia cuidadosa e limpesa rigirosa da região oferecem maior segurança ao paciente.

\section{PÓS OPERATÓRIO}

A responsabilidade da enfermeira no pós operatório nāo se limita aos cuidados gerais. $€$ de vital importância a atenção dirigida aos cuidados específicos.

\section{Posição da cama e controle do curativo}

Para facilitar a circulação de retorno e reduzir os riscos de hemorragia, o paciente deverá ficar em leve trendelemburgo nas primeiras 24 horas. Nas amputações abertas poderá ocorrer hemorragia maciça, razão pela qual a enfermeira verificará constantemente as condições do coto e fará controle de sinais vitais; como medida de prevenção deverá constar no material de emergência próximo do paciente um garrote ou torniquete que poderá se aplicado, até a chegada do médico, caso ocorra hemorragia no membro amputado. Os pontos que tracionam a pele do coto dererão ser verificados com frequência, pois poderão rompê-la aumentando a cor. Para que a tração atinja seu objetivo, é necessário que a cordinha corra livremente na roldana.

Nas amputações fechadas também poderão ocorrer hemorragias, que em geral são mais discretas. A verificação constante do curativo e dos sinais vitais são medidas iniciais indispensáveis. Freqüentemente, um reforço no enfaixamento reduz a hemorragia, até que o médico tome outras providências. 


\section{Posições do coto}

Os cotos de amputação abaixo do joelho não devem ficar apoiados sobre coxim para não provocar contratura em flexão. A razão é que os músculos flexores do joelho que se inserem na tíbia e no perôneo, estão com suas funções preservadas. O coxim irá manter a flexão, fortalecendo os flexores e enfraquecendo os extensores. Pelo mesmo motivo o paciente não deve ficar com o coto pendente no bordo da cama.

Os cotos de amputados acima do joelho também não deverão apoiar-se sobre coxim para evitar contratura dos músculos flexores da coxa. Dentre estes, o mais potente é o ileopsoas, que se origina nas vértebras e se insere no pequeno trocânter e cuja função não foi alterada. Inversalmente, os extensores: sartório, reto-femurais e quadriceps que se inserem abaixo do joelho, estão com suas funções prejudicadas, porque foram seccionados. Qualquer volume colocado sob o coto favorecerá a tendência para flexão, o que muito frequentemente provoca deformidade.

O coto, qualquer que seja o seu nivel, deverá permanecer em posição funcional, em alinhamento com a bacia. Os músculos, pequeno e médio glúteo, que se inserem na crista ilíaca e face externa do íleo e se estendem até o tracânter, exercem a função de abdutores. Como estão íntegros, favorecem a abdução. Nas amputações acima do joelho os músculos adutores estão seccionados porque suas inserções são ao longo do fêmur e portanto suas funções estão prejudicadas. Verifica-se, portanto, que não deverão ser colocados coxins entre o coto e a outra perna para prevenir contratura em abdução.

Os músculos abdominais que representam muito na manutenção da posição ereta do equeleto, e, para que possam exercer suas funcões, deverão permanecer contraídos. A colocação de um coxim na região lombar do paciente relaxa os músculos abdominais, que poderão tornar-se enfraquecidos.

Movimentação do paciente no primeiro dia pós operatório: Se a condição do paciente for favorável, a enfermeira solicitará sua participação por ocasião da higiêne corporal e da substituição das roupas de cama. A elevação do tronco, com auxílio do trapézio ou não, estimulará os músculos biceps e triceps. O paciente precisa aprender a usar a sua força e condicioná-la à sua atual massa corporal. A imagem que ele tem do seu próprio corpo é de integridade, levando-o a aplicar força superior à necessidade.

O paciente com amputação acima do joelho, já no segundo e terceiro dia pós operatório deverá ser ajudado a mudar para o decúbito ventral, posição que favorece o relaxamento dos músculos 
llexores da coxa, conforme já nos referimos. Para evitar dor e sojicitação dos músculos do coto, é necessário que este seja suportado pela enfermeira durante a movimentação. $O$ periodo de permanência em ventral deve ser aumentado progressivamente, assim como a participação do paciente na movimentação.

Os pontos da sutura, salvo indicação contrária, deverão ser removidos em torno de 10 a 12 dias, tempo normal de cicatrização da pele. A cicatrização dos inúsculos seccionados e suturados, ocorre em torno de seis semanas, razão pela qual deverão ser evitados movimentos bruscos que possam ocasionar contração muscular forte. Isto poderá provocar rompimento da sutura interna e aproximação da extremidade óssea da linha de sutura, forçando a cicatriz e ocasionando rompimento da pele.

Para a boa adaptação à prótese, o coto deve estar murcho, sem edema, o que se consegue com a colocação de enfaixamento compressivo, a partir do término da cirurgia. A absorção dos excudatos, a redução do tecido adiposo e a atrofia muscular são conseguidos graças a um enfaixamento de tensão bem distribuída, que não provoque zonas da constrição. O enfaixamento que mais atende à essa exigência é o tipo espiga.

Nos cotos curtos de fêmur, o enfaixamento deve incluir a circunferência abdominal, para não escorregar e perder sua função. Desaconselham-se o uso de esparadrapo em contato com a pele, para evitar irritação e escarificação.

Nas amputações de perna, os cotos deverão ser enfaixados de forma a deixar livre a articulação do joelho, para facilitar a movimentação.

E importante ressaltar que o processo de afunilamento do coto deve ser conseguido durante o período de cicatrização.

Quando o paciente refere sensação de queimação no coto, é necessário remover o enfaixamento para verificar as condições da pele.

\section{Cuidados com a pele do coto}

O paciente aprenderá com a enfermeira os cuidados especiais que deverá dispensar à pele do coto, quando deixar o hospital.

Após a remoção dos pontos, diariamente, o coto deverá ser cuidadosamente lavado com água morna e sabão neutro, sem deixá-lo imerso para evitar maceração. A secagem deve ser feita por compressão, procurando identificar zonas de irritação ou hiperemia. 
Com o objetivo de estimular a irrigação dos tecidos, procede-se à massagem leve, com substância emoliente, partindo da extremidade proximal do coto, em direção à linha de sutura.

\section{Membro remanescente}

Cuidados específicos serão dispensados ao membro restante, que exerce função vital no processo de deambulação do paciente amputado.

Limpeza diária com água morna e sabão. Secagem cuidadosa e verirficação sistemática do pé, para identificar hiperemia ou irritações. Manter as unhas curtas e retas.

Aplicação de substância emoliente em todo pé para evitar rachaduras.

\section{ADAPTAÇÃO À PRÓTESE}

Alguns autores preconizam que antes da indicação da prótese deve ser ouvida a opinião dos membros da equipe de profissionais que trabalham com o paciente.

Os pacientes geriátricos por exemplo, podem ser bem sucedidos na utilização da prótese, quando a sua indicação é precedida por criteriosa avaliação. A utilização contínua de muletas para a deambulação desse tipo de paciente, exige maior desgaste de energia do que o treinamento e uso de prótese. Estudos realizados nos EE.UU provam que pacientes geriátricos que tiveram como causa de amputação problemas circulatórios foram bem sucedidos com o uso de prótese, porque esta, funcionando como estímulo circulatório mantém o coto em boas condições de vitalidade. Portanto, a idade e a existência de alguns problemas de saúde por si só não devem impedir a indicação da prótese.

Outro fator a ser considerado por ocasião da indicação da prótese é a ocupação ou profissão do paciente, porém este aspecto será mencionado mais adiante.

Durante o período de treinamento com prótese, o paciente gasta muita energia, ocasionando cansaço. Ao lado das dificuldades físicas, sabe-se que é penoso para o paciente aceitar a substituição de um membro por um mecanismo de metal, plástico e couro, aumentando o seu estado de tensão.

Referem os autores que o ajustamento é mais fácil nos pacientes cuja sensação de "Membro Fantasma" persiste, uma vez que a prótese substitui uma parte do seu corpo. O outro grupo de pacientes 
que não refere a sensação de "Membro Fantasma", considera a prótese como um meio de locomoção que ele precisa aprender a usar com habilidade.

Há algumas particularidades que o paciente precisa conhecer e aplicar e se referem à proteção da pele do coto durante o uso da prótese, quais sejam: - revestir o coto com meia de tecido de malha de algodão ou de lã, apropriada ao seu formato e tamanho, possuir quantidade suficiente de meias, de forma a permitir duas trocas diárias, prevenindo umidade da pele do coto; a meia deve ser íntegra, sem dobras ou costuras em contato com a pele. Para garantir a flexibilidade e maior durabilidade. da meia," lavá-la com água morna e sabão e não passá-la a ferro.

Nas amputações que exigem prótese longa com cinto pélvico, o paciente deve usar uma camiseta e, sobre esta, colocar o cinto para evitar desconforto e escarificação da pele.

\section{PREPARO PARA A INDEPENDÊNCIA}

Esta fase deve ser iniciada o mais precoce possível, já nos primeiros dias de pós-operatório, e progredir de tal forma, que a dependência para a realização de cuidados pessoais seja mínima.

Quando se aproxima a época da alta, e o paciente já atingiu ao máximo a sua independência, outras medidas de enfermagem deverão ser adotadas. Será convocado um familiar ou a pessoa que irá conviver com o paciente, para aprender com a enfermeira alguns aspectos essenciais para a continuidade de sua assistência no lar.

Uma vez que os banhos de imersão são contra-indicados para não macerar a pele do coto, o paciente deverá tomar banho diário de chuveiro, sentado numa cadeira firme. Ele deverá sentar-se na cadeira, para retirar as roupas e a prótese; esta deverá ficar próxima ao paciente, para que seja colocada logo após o banho. Para secar o corpo e recolocar a prótese, o paciente deverá manter-se sentado.

Os pacientes amputados ao nível do fêmur deverão vestir-se sentados, obedecendo a uma seqüência que facilite a sua atividade. Inicialmente vestir uma camiseta, a seguir vestir a meia e ajustar a prótese, do coto fixando o cinto pélvico sobre a camiseta.

Vestir a cueca ou calcinha sobre a prótese. Poderá haver escorregamento do cinto pélvico, se esta sequência for invertida.

Para colocar as calças, vestir primeiro o membro com a prótese e a seguir o outro; para despí-las, atuar de forma inversa. 
Na ocasião do preparo para a alta, os cuidados específicos com a pele do coto deverão ser executados pelo paciente, na presençà do familiar e da enfermeira, que reforçará os pontos importantes. O familiar deverá aprender a lavar, secar, massagear e fazer a verificação da pele do coto.

A atenção zelosa com a prótese aumenta a sua durabilidade e garante seu funcionamento.

E essencial que o familiar veja o paciente executando todas as atividades comuns com destreza, para não assumir atitudes de superproteção. O paciente sente-se valorizado quando as pessoas reconhecem seu esforço.

\section{RETORNO AO TRABALHO}

Este é um dos importante aspectos do processo de Reabilitação do cliente amputado, e provavelmente a última etapa a ser atingida: A insegurança em enfrentar o grupo de trabalho e a sociedade é uma reação natural que ele apresenta. O aspecto de retorno ao trabalho exige a participação na equipe de um profissional habilittado para oferecer ao paciente a ajuda que ele necessita.

Atuando de forma natural, sem exigir em excesso e sem superproteção, a família, o empregador e os colegas de trabalho estarão contribuindo para a reintegração do indivíduo amputado à vida normal.

E importante que seu potencial e suas habilidades sejam reconhecidas e utilizadas para tornar mais rápida a sua reintegração.

Finalizando nossas considerações, citaremos 7 necessidades que o indivíduo amputado pode apresentar segundo sidney Fishiman (4).

1 - Função física: - o amputado não deseja consideração especial; deseja participar das atividades normais sem restrições e frustrações;

2 - Aparência física: - não quer ser diferente dos demais indivíduos do grupo; necessita de próteses bem adequadas e funcionaiš que não prejudiquem sua imagem corporal;

3 - Conforto: - deseja sentir-se bem apoiado pela prótese, sem dor e claudicação; a dor provoca desconforto, modifica o comportamento, tornando o indivíduo tenso e irritado;

4 - Energia física: - o uso da prótese exige um desgaste maior de energia, levando à fadiga mais precocemente, fator de frustraçãŏ para c amputado; é necessário reconhecer este aspecto e não compará-1o com os demais indivíduos; 
$\therefore$ 5. - Sucesso: - as experiências negativas relacionadas com os fracassos públicos anteriores, inibem o amputado a participar de atividades de grupo;

6 - Segurança econômica: - como suas possibilidade de trabalho podem estar reduzidas e existe competição no mercado de trabalho, o indivíduo amputado sente maior necessidade de segurança econômica.

7 - Respeito e status: - esta é talvez a mais importante das necessidades sentidas pelo amputado, que é membro da comunidade e precisa ajustar-se a ela.

É a partir deste ajustamento que se pode afirmar que o processo de Reabilitação foi bem sucedido.

A enfermeira que se manteve desde o início do tratamento, junto ao paciente, promovendo comunicação efetiva, aliviando tensão, prevenindo deformidades, atrofias musculares e infecções; ensinando ao paciente e familiar aspectos de independência em atividades pessoais, acompanha com o olhar o indivíduo que caminha seguro em direção de uma nova etapa de sua vida.

\section{RESUIMO}

Tentamos focalizar a responsabilidade da enfermeira na assistência prestada ao paciente amputado, tornando como objetivo o seu retorno à família, ao trabalho e à comunidade.

São fatorês de suceśso do amputado:

1 - cirurgia correta

2 - assistência de enfermagem que previne contraturas e que prepare o coto para a prótese.

3 - apoio psicológico.

4 - prótese bem adaptada e funcional.

5 - emprego produtivo e ajustado às suas condições.

\section{BIBLIOGRAFIA}

1 - BECHTOL, Charles O, M. D. - Industrial amputee Rehabilitation Sponsored by liberty mutual insurance Company of Boston.

2 - BELLIBONI, Diomede - Estudo comparativo das próteses PTB e KBM. Tese apresentada na Faculdade de Medicina da Universidade de São Paulo em 1973.

3 - BONNER, Charles D. M. D. and LYFORD Berenice E., R. P. T. Muscle Rehabilitation by steroid therapy and sling suspension. Holy ghost Hospital Rehabilitation Unit. Cambridge, Massachusetts. 1959.

4 - GALLAGHER, Kathleen M. - Nursing care of the amputee - Boston University Labory. 1964.

5 - RUSK, H. A., TAYLOR, E. J. - Living with disability - The Blakiston Company, Inc. Garden City, N.Y. 1953. 